\title{
'Omics' Approaches to Understanding Interstitial Cystitis/Painful Bladder Syndrome/Bladder Pain Syndrome
}

\author{
Sungyong You ${ }^{1}$, Wei Yang ${ }^{1}$, Jennifer T. Anger ${ }^{2}$, Michael R. Freeman ${ }^{1,3,4}$, Jayoung Kim ${ }^{1,3,4}$ \\ ${ }^{1}$ Division of Cancer Biology and Therapeutics, Departments of Surgery and Biomedical Sciences, Samuel Oschin Comprehensive Cancer Institute, \\ Cedars-Sinai Medical Center, Los Angeles, CA; \\ ${ }^{2}$ Department of Surgery, Cedars-Sinai Medical Center, Center for Women's Continence and Pelvic Health at Cedars-Sinai, Los Angeles, CA; \\ ${ }^{3}$ The Urological Diseases Research Center, Boston Children's Hospital, Boston, MA; \\ ${ }^{4}$ Departments of Surgery and Biological Chemistry and Molecular Pharmacology, Harvard Medical School, Boston, MA, USA
}

\begin{abstract}
Recent efforts in the generation of large genomics, transcriptomics, proteomics, metabolomics and other types of 'omics' data sets have provided an unprecedentedly detailed view of certain diseases, however to date most of this literature has been focused on malignancy and other lethal pathological conditions. Very little intensive work on global profiles has been performed to understand the molecular mechanism of interstitial cystitis/painful bladder syndrome/bladder pain syndrome (IC/PBS/BPS), a chronic lower urinary tract disorder characterized by pelvic pain, urinary urgency and frequency, which can lead to long lasting adverse effects on quality of life. A lack of understanding of molecular mechanism has been a challenge and dilemma for diagnosis and treatment, and has also led to a delay in basic and translational research focused on biomarker and drug discovery, clinical therapy, and preventive strategies against IC/PBS/BPS. This review describes the current state of 'omics' studies and available data sets relevant to IC/PBS/BPS, and presents opportunities for new research directed at understanding the pathogenesis of this complex condition.
\end{abstract}

Keywords: Interstitial cystitis; Omics; Medical informatics; Physiopathology

\section{INTRODUCTION}

\section{Diagnosis and Treatment of Interstitial Cystitis}

Interstitial cystitis/painful bladder syndrome/bladder pain syndrome (hereafter IC) is a chronic disorder of the urinary bladder that manifests as long-term symptoms of pelvic and or perineal pain, thinning or ulceration of the bladder epithelial lining, nocturia, urinary frequency, and urgency [1-3]. Approximately 3 to 8 million women and 1 to 4 million men in the US have been diagnosed with IC [1,2], and IC significantly reduces the quality of life of patients and suppresses physical function and social activity. The financial burden and medical cost associated with IC is increasing and is currently estimated to exceed $\$ 100$ million/yr [4]. However, etiologies are largely unknown and effective treatment or medications have not been found.

Patients are diagnosed with IC by the presence of certain cli- nical features (e.g., symptoms of urinary urgency, frequency, and chronic pelvic pain, urodynamics, potassium sensitivity assay, cystoscopic bladder evaluation) in the absence of other identifiable causes for similar symptoms (e.g., urinary tract infection). Diagnosis is generally made according to recent the National Institute of Diabetes and Digestive and Kidney Diseases and American Urological Association guidelines [3,5-8]. Histological analysis of bladder biopsies obtained from IC patients has been reported to show a thinning of the urothelial layers and an increased infiltration of mast cells, suggesting that the disease is mediated by a defect in the regenerative potential of bladder epithelial cells, and/or by immune impairment [1,2]. Although there are multiple hypotheses about the primary cause of IC, the underlying pathologic mechanism remains completely undefined, leading to delays in identifying effective therapeutic modalities. Approaches to the treatment of IC have included
Corresponding author: Jayoung Kim

Division of Cancer Biology and Therapeutics, Departments of Surgery and Biomedical Sciences, Samuel Oschin Comprehensive Cancer Institute, CedarsSinai Medical Center, 8700 Beverly Blvd., Los Angeles, CA 90048, USA Tel: +1-310-423-7168 / Fax: +1-310-967-3809 / E-mail: Jayoung.Kim@cshs.org Submitted: December 17, 2012 / Accepted after revision: December 18, 2012
This is an Open Access article distributed under the terms of the Creative Commons Attribution Non-Commercial License (http://creativecommons.org/licenses/by-nc/3.0/) which permits unrestricted non-commercial use, distribution, and reproduction in any medium, provided the original work is properly cited. 
procedures such as hydrodistension, and oral pharmaceutical drugs such as pentosan polysulfate (Elmiron, the U.S. Food and Drug Administration approved), antihistamines, tricyclic antidepressants, and immune modulators. In general, symptom relief with any of these strategies has been reported in only a small percentage of patients and recurrence typically is evident within a few months [1,9].

\section{Molecular Signature of IC}

In IC patients, several abnormalities were observed in epithelial, endothelial, smooth muscle (detrusor), neuronal, or immune cells, compared to controls. In particular, histological characteristics of IC include thinning or erosion of the bladder epithelium. Proliferation is suppressed [10] and cell permeability is altered in urothelium from IC patients [11,12], compared to controls. At the molecular level, expression of pro-proliferative proteins (e.g., cyclin D1) and barrier tight junction proteins (e.g., zonula occludens-1, occludin, and claudin 1,4 , and 8 ) is dysregulated [11,12]. IC bladder epithelial cells exhibited intrinsic alteration in differentiation, neurotransmitter release and potassium channel activity, with elevated nitric oxide production, nuclear factor $\kappa \mathrm{B}(\mathrm{NF}-\kappa \mathrm{B})$ activation, nerve fiber number, serum $\mathrm{C}$-reactive protein, neuropeptide $\mathrm{Y}$ and nerve growth factor production [13-15]. Bladder endothelial abnormalities in IC include increased levels of platelet derived endothelial cell growth factor/thymidine phosphorylase, vascular endothelial growth factor, and substance P expression [16-18].

A unique urinary biomarker of IC, a small glycopeptide named antiproliferative factor (APF), was originally identified and characterized by Keay et al. [19] APF bioactivity is increased in urine specimens of IC patients and measurement of APF in urine identifies IC with $94 \%$ sensitivity and $95 \%$ specificity [2022]. APF has been suggested as a potential mediator of IC symptoms by regulating important signaling pathways, such as Akt, mitogen-activated protein kinase, $\beta$-catenin or p 53 signaling, leading to suppression of cell proliferation and increases in transurothelial cellular permeability [19,23-25]. In order to understand the APF signaling network in a global way, a recent quantitative proteomics and systems biology approach was employed that identified a provisional APF network and several apparently key signaling nodes in urothelial cells downstream from APF [23,25-28]. Because we have described this APF signaling network in IC in a recent review [26], we will not cover signaling mechanisms perturbed by APF here.

\section{GENOMICS STUDIES}

In some cases IC is a comorbid condition associated with other pathologies. According to the results from the Interstitial Cystitis Database Study, a 5-year prospective cohort study of more than 600 men and women with symptoms of urinary urgency, frequency, and pelvic pain, up to $40 \%$ of patients may suffer also from allergic diseases [29]. Autoimmune diseases such as systemic lupus erythematosus and Sjogren's syndrome are also observed in the IC population at significantly increased rates [30]. To test the hypothesis that IC symptoms may be affected by activation of autoimmune mechanisms, Sugaya et al. [31] looked at polymorphisms known to increase risk of other autoimmune conditions in IC patients, focusing on specific allelic variants in interleukin-4 (IL-4)/IL-4 receptor and adrenergic receptor genes [31].

Application of linkage studies to IC provided genetic evidence that the disease can track with autosomal and complex inheritance patterns. Dimitrakov [32] and Dimitrakov et al. [33] described several families with familial clustering of IC. Analysis of results obtained from this group of families was consistent with the previously published results of increased familial clustering of IC [29]. The authors identified 20 Bulgarian families with apparent autosomal dominant inheritance of IC using genome-scale single nucleotide polymorphism (SNP) arrays. This study presented an opportunity to uncover candidate genes for IC inherited from a single individual (the so-called founder effect [33]), suggesting that inherited genetic susceptibility is a key component of IC etiology.

Recent advances in genome-scale high-throughput technologies, such as microarray and whole genome sequencing, allow in-depth assessment of genetic variation. Genome-wide association studies seek to identify the SNPs, as well as structural variations including deletions, insertions, copy-number variations, and genomic translocations, that are common to the human genome and to determine how these polymorphisms are distributed across different populations [34,35]. Most genetic studies on IC have used a single-locus analysis strategy $[31,36]$, however if a genetic factor functions primarily through a complex mechanism that involves multiple other genes, the effect might be missed if the gene is examined in isolation without allowing for its potential interactions with these other unknown factors. For this reason, the existence of interaction between variant loci should be considered to achieve a success in genetic studies of IC. Currently, several methods and software packages can be 
used to quantitatively examine interactions between loci and their statistical significance when analyzing the data from genetic association studies [37].

The current state of genomic information on IC is limited to specific markers such as genes associated with autoimmune properties. Application of state-of-the-art genomic technologies and accumulation of large genomics data sets will allow the discovery of clinically useful genetic markers, and may lead to a comprehensive understanding of pathogenesis associated with common genetic variations.

\section{FEATURES OF CURRENT TRANSCRIPTOME DATA SETS}

Transcriptome profiling has allowed the discovery of global gene expression patterns that correlate with disease phenotypes and provides a cellular and physiologic context for pathogenic conditions at the system level. Molecular profiling of blood cells, urine sediments, and bladder biopsy specimens has already revealed important pathways that contribute to the spectrum of IC (Table 1). Transcriptome profiles from bladder tissues, urine sediments, and peripheral blood mononuclear cells (PBMCs) from healthy individuals, asymptomatic bladder disorders, and/or IC patients have been reported.

In order to begin to assemble a global gene signature for IC, we compared and analyzed these datasets, despite significant limitations in data quality and small sample sizes. Fig. 1A shows the relationships between 1) 2,325 genes differentially expressed in five IC bladder tissues compared to six healthy controls, 2) 837 genes differentially expressed in urine sediment of five IC patients compared to five healthy controls, and 3) PBMCs of twenty one overactive bladder patients (whose symptoms generally overlapped with IC symptoms) compared to six healthy controls. From the 2,886 genes in this combined series, 276 genes are significantly changed both in tissues and biofluids (e.g., urine or PBMC), compared to controls. Fig. 1B shows the cellular processes enriched by these commonly deregulated genes. The up-regulated genes are primarily involved in innate immune-related processes (e.g., chemotaxis, antigen processing and presentation, regulation of cytokine production, actin immunoglobulin-mediated immune response, and coagulation). Lipid biosynthetic processes, muscle contraction, and actin cytoskeleton organization were enriched in the down-regulated gene category. Along with this analysis, two sets of biomarker candidates were selected using methods that assess functional association, degree of interactions, and expression patterns. Among the genes involved in these IC-associated cellular processes, five genes (IL1B, interleukin 1B; CD74, cluster of differentiation 74; PLAT, plasminogen activator; CALD1, caldesmon 1; and TPM, tropomyosin) were identified as a first set of candidates that might reflect the underlying pathology of IC (Fig. 1B). These genes are associated with a broad range of the enriched cellular processes and can be identifiably networked with other genes. Furthermore, we selected seven genes $(C Y$ P27A1, a cytochrome P450 oxidase; GBP1, guanylate-binding protein 1; STAT1, signal transducer and activator of transcription 1; LCP1, lymphocyte cytosolic protein1; PTGDS, prostaglandin-H2 D-isomerase; KRT4, keratin 4; and CFB, complement factor $B$ ) as a second set of IC biomarker candidates. These seven genes were also identified in plasma based on search through Human Plasma Proteome Project Data Central [38,39] (Fig. 1C).

\section{PROTEOMICS STUDIES}

\section{Biomarker Discovery}

Proteins are the major executors of life activities and are several steps closer to influencing a person's health than DNA and even RNA. Thus, proteins frequently have the greatest clinical significance for the diagnosis of diseases. Studies in the field of pro-

Table 1. Transcriptome data sets used for data integration in this paper

\begin{tabular}{lccc}
\hline & No. of samples & GEO ID & Reference \\
\hline Bladder tissues (human) & $\begin{array}{l}\text { Healthy control }(\mathrm{n}=6) \text {, interstitial cystitis with ulcer }(\mathrm{n}=5) \text {, interstitial cystitis } \\
\text { without ulcer }(\mathrm{n}=5)\end{array}$ & GSE11783 & [76] \\
Urine sediment (human) & $\begin{array}{c}\text { Healthy control }(\mathrm{n}=5) \text {, lesion-free }(\mathrm{n}=5) \text {, and hunner lesion bearing }(\mathrm{n}=3) \\
\text { painful bladder syndrome patients }\end{array}$ & GSE28242 & [77] \\
$\begin{array}{l}\text { Peripheral blood mononuclear } \\
\text { cells (PBMCs, human) }\end{array}$ & Healthy control $(\mathrm{n}=6)$, overactive bladder patients $(\mathrm{n}=21)$ & - \\
\hline
\end{tabular}

GEO, gene expression omnibus; GSE, the genomic spatial event database; PBMC, peripheral blood mononuclear cell. 


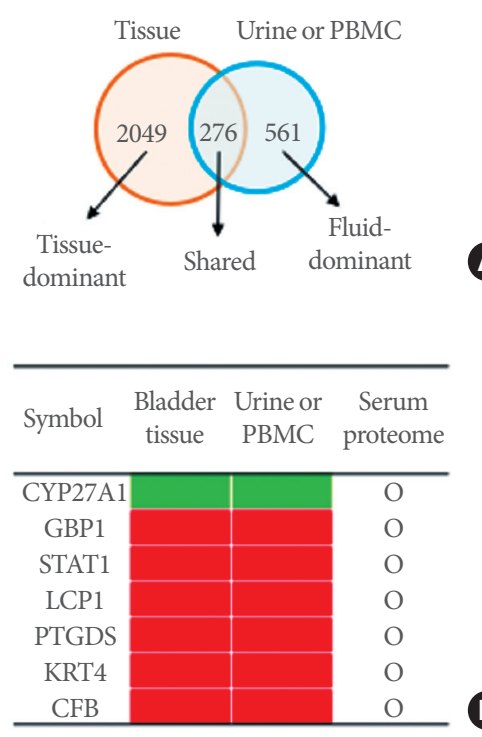

\begin{tabular}{|c|c|c|}
\hline Class & Terms & Involved genes \\
\hline \multirow{8}{*}{$\begin{array}{l}\text { Up-reg- } \\
\text { ulated }\end{array}$} & Chemotaxis & $\begin{array}{l}\text { DOCK2, CYSLTR1, IL1B, } \\
\text { ITGB2, CXCL6, CXCL11 }\end{array}$ \\
\hline & $\begin{array}{l}\text { Antigen processing and } \\
\text { presentation }\end{array}$ & $\begin{array}{l}\text { HLA-DQB1, HLA-DMB, HLA-DMA, PSMB8, } \\
\text { HLA-DQA1, CD74, HLA-F, PSMB9, TAP2, } \\
\text { HLA-DPA1, HLA-DOA, HLA-DOB, HLA-DRA }\end{array}$ \\
\hline & $\begin{array}{l}\text { Regulation of cytokine } \\
\text { production }\end{array}$ & CD86, IRF1, IL1B, IDO1, TLR8 \\
\hline & $\begin{array}{l}\text { Immunoglobulin mediated } \\
\text { immune response }\end{array}$ & HLA-DMA, TLR8, CD74, HLA-DRA \\
\hline & $\begin{array}{l}\text { Integrin-mediated signaling } \\
\text { pathway }\end{array}$ & ITGAL, PLEK, ITGB2, ITGA4 \\
\hline & Cell migration & $\begin{array}{l}\text { PLAT, DOCK2, PARP9, IL1B, ITGB2, } \\
\text { ITGA4, MSN, SELPLG }\end{array}$ \\
\hline & Coagulation & PLAT, PLEK, ENTPD1 \\
\hline & Proteolysis & $\begin{array}{l}\text { PLAT, CTSZ, CPM, BMP1, CFB, GZMB, } \\
\text { MMP12, PSMB8, PSMB9, CASP10, } \\
\text { GZMK,ATG4A, UBD }\end{array}$ \\
\hline \multirow{3}{*}{$\begin{array}{l}\text { Down- } \\
\text { regulated }\end{array}$} & Lipid biosynthetic process & CWH43, HMGCS2, PGAP1 \\
\hline & Muscle contraction & CALD1, TPM1 \\
\hline & $\begin{array}{l}\text { Actin cytoskeleton } \\
\text { organization }\end{array}$ & ARHGAP6, CALD1, TPM1 \\
\hline
\end{tabular}

Fig. 1. Transcriptome profiles of interstitial cystitis. (A) Venn diagram depicts the overlap of differentially expressed genes between bladder tissues and urine or peripheral blood mononuclear cells (PBMCs). (B) Cellular processes enriched by commonly deregulated genes. Genes that are shaded with red or green color have large number of interactions with other genes in those enriched processes. (C) List of genes as biomarker candidates that have been detected in tissues, urine and serum. Red and green represent up- and downregulation in bladder tissues and urine or PBMCs, compared to controls. 'o' means positivity of detection in human serum proteome $[38,39]$.

teomics aim to systematically catalog and understand the identity, quantity, modification, localization, interaction, and function of all proteins in a cell or organism [40]. In the past two decades, a number of powerful proteomics technologies were developed to comprehensively compare the protein differences between patients suffering from a wide range of ailments and healthy controls to discover biomarkers for diagnosis, prognosis, and monitoring treatment response.

Surface-enhanced laser desorption/ionization time-of-flight mass spectrometry (SELDI-TOF MS) technology was developed in 1993 [41] and later commercialized as the ProteinChip system. This method combines surface-enhanced selective capture with high-sensitivity TOF MS for protein profiling, biomarker discovery, and immunoassay applications. SELDI-TOF MS is a high-throughput technology-assays can be performed in 96-well microplates and only limited preprocessing is required. In 2003, Van et al. [42] used weak cation exchange ProteinChip arrays as well as high-resolution proton nuclear magnetic resonance (NMR) to profile proteins and metabolites of urine samples obtained from 50 patients with IC, 30 patients with acute bacterial cystitis, and 50 asymptomatic controls. They found that urine samples obtained from healthy vs. IC-affected individuals can be segregated using eight different mass-to-charge $(\mathrm{m} / \mathrm{z})$ values.

Two-dimensional electrophoresis (2DE) coupled with matrix assisted laser desorption/ionization time-of-flight (MALDI-TOF) MS is a widely used proteomics approach. 2DE is a high-resolution protein separation method that sorts proteins according to two independent properties (i.e., isoelectric point and mass) [43]. After 2DE separation, gels are treated with a protein stain (Coomassie, silver, or SYPRO) to visualize protein spots. Gel images are analyzed using software to identify differentially expressed protein spots. To reduce the inter-gel variation, a method called two-dimensional difference gel electrophoresis (2DDIGE) was developed in 1997 [44]. In this method, up to three different protein samples can be differentially tagged with chemically similar fluorescent dyes (e.g., Cy3, Cy5, or Cy2), mixed, and resolved on the same $2 \mathrm{D}$ gel. The gel is scanned with the excitation wavelength of each dye one after the other, so the gel image derived from each sample can be obtained separately and compared. After gel electrophoresis and image analysis, protein spots of interest (e.g., differentially expressed proteins) are ex- 
cised and digested with an endoproteinase (e.g., trypsin) to generate peptides. The resulting peptides are mixed with a matrix (e.g., a-cyano-4-hydroxycinnamic acid) solution and the mixture is spotted onto a MALDI plate and analyzed with a MALDI-TOF MS to generate a peptide-mass fingerprint, which serves to identify the protein spot. The peptides can also be analyzed with nano-liquid chromatography-tandem mass spectrometry (nanoLC-MS/MS) to sequence each peptide and thus identify the protein [40].

Canter et al. [45] used 2DE to resolve proteins in urine samples from nine IC patients and nine asymptomatic controls. Four protein spots were significantly differentially expressed between the IC group and the control group. Subsequent MALDI-TOF analysis identified the protein spots significantly downregulated in the IC group as a uromodulin and two kininogens (precursors of kinin) and the protein spot significantly upregulated in the IC group as inter- $\alpha$-trypsin inhibitory heavy chain H4. Kuromitsu et al. [46] applied the 2D-DIGE method to compare proteins in urine samples from three IC patients and three healthy subjects. Several protein spots around $40 \mathrm{kDa}$ were significantly increased in the IC group. These proteins were identified as fragments of human serum albumin by nano LC-MS/ MS. Subsequently, the protease cleaving albumin was purified and identified as neutrophil elastase. The comparison of neutrophil elastase activity in urine samples of 86 IC patients and 89 healthy controls showed that the concentration of neutrophil elastase was significantly higher in an IC patient subset with bladder pain and small bladder capacity than in other IC patients and healthy controls. Lemberger et al. [47] applied 2DE to separated urine supernatants of eighteen cats with spontaneous feline idiopathic cystitis (FIC), a cat model of IC, and eighteen healthy controls. MALDI-TOF/TOF analysis identified ten spots significantly upregulated in the FIC group as albumin and one spot significantly downregulated in the FIC group as trefoil factor 2 [47].

Although the 2DE technology has many advantages such as robustness, the ability to run gels in parallel, and the unique ability to analyze complete proteins at high resolution, it has its intrinsic limitations, most importantly that low-abundance and hydrophobic proteins are difficult to detect [43]. To overcome these limitations, nanoLC-MS/MS has been developed and dramatically improved. Currently, using the nanoLC-MS/MS approach and high-end mass spectrometers, over 10,000 proteins can be identified from human cancer cells as well as archival formalin fixed and paraffin embedded clinical samples [48-
50].

Kuromitsu et al. [46] reported on an active substance in urine from IC patients that drives the expression of the serum response element-dependent luciferase reporter gene in GPR18-expressing HEK293 cells. This material was identified by nanoLC-MS/ MS as epidermal growth factor. Goo et al. [51] compared the urinary proteome of ten IC patients and ten healthy controls. A total of 889 and 1,003 proteins were identified from IC patients and healthy controls, respectively, using LC-MS/MS. Among the 78 significantly changed proteins, $\alpha-1 \mathrm{~B}$-glycoprotein and orosomucoid-1 were upregulated in at least $60 \%$ of IC patients compared to control subjects. In contrast, transthyretin and hemopexin were decreased in at least $60 \%$ of IC patients compared to healthy controls.

In summary, much effort has been made to identify and characterize potential urinary biomarkers for IC by proteomic analysis of a relatively small number of specimens. Complimentary to the high-content but low-throughput discovery MS methods, recently developed targeted MS methods allow fast and multiplex assays of candidate biomarkers with high sensitivity and accuracy [52]. It is anticipated that the candidate IC biomarkers will be validated in a large number of urine samples using targeted MS in the near future. In addition to biomarker discovery, quantitative proteomics methods will be increasingly applied to dissect the signaling networks perturbed in IC, thus opening up new avenues to the identification of novel drug targets.

\section{METABOLOMICS PROFILES}

\section{Urinary Metabolites as Disease Biomarkers}

For the diagnosis of IC, invasive procedures such as cystoscopy and the potassium sensitivity test and the noninvasive use of biofluids (e.g., urine, blood, saliva, fecal extract, and sputum specimens)-based assays have both been used. The best diagnostic test would include noninvasive biomarker(s) with high sensitivity and specificity. Urine-based diagnosis is attractive, since it is noninvasive with no required preparation by the patient. Global profiling of urinary metabolites using MS or NMR has been attempted $[42,53]$. NMR spectroscopy, which detects the resonance of a particular substance within a magnetic field, can provide structure as well as quantitative and qualitative information with great reproducibility and sensitivity [53-55]. Sample preparation steps for NMR analysis are simple, which is a great advantage for clinical applications but the sensitivity of 
NMR-based metabolomics analysis is less than MS-based metabolomics. In attempts to detect low abundance metabolites, several approaches have been tried, such as increasing NMR magnetic field strength, to enhance the sensitivity of NMR technology. Metabolic profiling provides a global chemical fingerprint of the physiology and metabolism of cells, and indicates physiological and pathological states of biological samples.

A few attempts to use metabolomics analysis to identify an IC signature have been published. Fukui et al. [53] used ultraperformance liquid chromatography-mass spectrometry and found that the urinary ratio of phenylacetylglutamine to creatine can be correlated to clinical grade of IC (e.g., mild to severe based on symptoms) [53]. In 2003, Van et al. [42] has suggested that MS and NMR spectral patterns distinguish IC-affected from non-IC patients including bacterial cystitis. With further validation in a larger cohort, global metabolite profiling combined with multivariate statistical and bioinformatics analysis would suggest important biomarker metabolites contributing to the biological responses such as the drug-induced toxicity or response as metabolic biomarkers.

\section{COMPUTATIONAL BIOLOGY FOR INTEGRATIVE ANALYSIS}

One of the key issues in developing a computational approach to complex diseases is how to maximally extract disease-relevant information using integration of various 'omic' datasets derived from genomics, trancriptomics, proteomics, and metabolomics methods, and to apply extracted information to clinical settings [56]. Emerging multiple 'omics' resources and technologies are revolutionizing biomedical research. The systems approach assumes that the majority of biomolecules function through complex networks. Recent studies show that the data from multiple 'omic' sources is complementary to each other or mandatory to obtain system level understanding [57, 58]. Currently, biological networks are normally used as a multiomics data integration platform to capture the emergent properties in disease perturbed networks [59,60]. Therefore, the systems approach integrating multi-omics data using network heuristics will increase the reliability of discovering biomarkers and therapeutic targets for IC. Here, we briefly describe computational methods and tools that are likely to be of particular importance in identification of molecular targets and biomarker candidates.

\section{Identification of Disease-Associated Molecules and Construction of Network Models}

To identify disease-associated molecules, various types of feature selection procedures can be employed. In most cases, multiple hypotheses testing with false discovery rate control procedures are applied for various types of 'omics' data. In order to subgroup and select molecules with significant difference of measurement or large variability in subset of samples, a cluster analysis or discriminant analysis can be alternatively used. To translate the identified molecular signature into biologically meaningful hypotheses, functional enrichment analysis by Bioconductor [61], DAVID (Database for Annotation, Visualization and Integrated Discovery) and GSEA (gene set enrichment analysis) software can be used [62-64]. To identify a subset of molecules associated with diseases, several useful resources including Gendoo (gene, disease features ontology-based overview system), Genotator, and Metabolite Set Enrichment Analysis (MSEA) can be applied [65-67]. To construct a diseaseperturbed network, several stand alone software and web-based tools can be useful, including: 1) integrative querying systems for interaction information (PSICQUIC [68]); 2) network modeling and analysis tools (STRING [69] and Cytoscape [70]); and pathway analysis (KEGG [71]). In addition to these instruments, other commercial tools such as GeneGo and Ingenuity Pathway Analysis (IPA) can be used to reconstruct a network, as well as identify significantly enriched pathways characterized by key network nodes.

\section{Identification of Potential Molecular Targets and Indicators}

Once network models are developed as described above, the network can be queried to select potential target molecules using two types of network analysis algorithms including 1) random walk algorithms and 2) master regulator analysis for prioritizing key molecules. The random walk approach has been applied to detecting disease genes related to a wide range of diseases [72,73]. Master regulator analysis is generally used to find a key transcription factor that has the largest number of targets using transcription factor-target and protein-protein interaction data $[74,75]$.

\section{CONCLUDING REMARKS}

IC is a chronic bladder condition that significantly reduces quality of life of women and men. Diagnostic and treatment modalities, even subjective diagnostic tools, are largely unavail- 
able. As described here, our attempts to perform a systematic review and to build a pooled database using existing public 'omics' data associated with IC revealed the significant limitations and challenges facing investigators in the field. IC is an understudied area because of limited research funding, lack of clear diagnostic criteria to stratify patients, the lack of established and well-curated biorepositories, and insufficient scientific interest by the translational scientific community. Computational approaches combined with high quality 'omics' data could provide new insights in the field and essential molecular details about regulatory mechanisms and perturbations leading to IC, an essentially required regulatory mechanism of IC, essential information if we are to offer improved diagnostic capability and treatment strategies for patients.

\section{CONFLICT OF INTEREST}

No potential conflict of interest relevant to this article was reported.

\section{ACKNOWLEDGEMENTS}

The authors acknowledge support from National Institutes of Health grants R37 DK47556, R01 DK57691, P50 DK65298 (to MRF) and the Fishbein Family IC Research Foundation/Interstitial Cystitis Association; New York Academy of Medicine; and Children's Hospital Boston Faculty Development (to JK); J.K. is an American Urological Association Foundation Research Scholar and an Eleanor and Miles Shore Scholar of Harvard Medical School.

\section{REFERENCES}

1. Persu C, Cauni V, Gutue S, Blaj I, Jinga V, Geavlete P. From interstitial cystitis to chronic pelvic pain. J Med Life 2010;3:167-74.

2. Phatak S, Foster HE Jr. The management of interstitial cystitis: an update. Nat Clin Pract Urol 2006;3:45-53.

3. Hanno P, Levin RM, Monson FC, Teuscher C, Zhou ZZ, Ruggieri M, et al. Diagnosis of interstitial cystitis. J Urol 1990;143:278-81.

4. Anger JT, Zabihi N, Clemens JQ, Payne CK, Saigal CS, Rodriguez LV. Treatment choice, duration, and cost in patients with interstitial cystitis and painful bladder syndrome. Int Urogynecol J 2011;22: 395-400.

5. Hanno P, Keay S, Moldwin R, Van Ophoven A. International Consultation on IC - Rome, September 2004/Forging an International
Consensus: progress in painful bladder syndrome/interstitial cystitis. Report and abstracts. Int Urogynecol J Pelvic Floor Dysfunct 2005;16 Suppl 1:S2-34.

6. Ness TJ, Powell-Boone T, Cannon R, Lloyd LK, Fillingim RB. Psychophysical evidence of hypersensitivity in subjects with interstitial cystitis. J Urol 2005;173:1983-7.

7. Nordling J, Anjum FH, Bade JJ, Bouchelouche K, Bouchelouche P, Cervigni $\mathrm{M}$, et al. Primary evaluation of patients suspected of having interstitial cystitis (IC). Eur Urol 2004;45:662-9.

8. Hanno PM, Burks DA, Clemens JQ, Dmochowski RR, Erickson D, Fitzgerald MP, et al. AUA guideline for the diagnosis and treatment of interstitial cystitis/bladder pain syndrome. J Urol 2011;185:216270.

9. Hanno PM. Analysis of long-term Elmiron therapy for interstitial cystitis. Urology 1997;49(5A Suppl):93-9.

10. Keay S, Zhang CO, Shoenfelt JL, Chai TC. Decreased in vitro proliferation of bladder epithelial cells from patients with interstitial cystitis. Urology 2003;61:1278-84.

11. Slobodov G, Feloney M, Gran C, Kyker KD, Hurst RE, Culkin DJ. Abnormal expression of molecular markers for bladder impermeability and differentiation in the urothelium of patients with interstitial cystitis. J Urol 2004;171:1554-8.

12. Zhang CO, Wang JY, Koch KR, Keay S. Regulation of tight junction proteins and bladder epithelial paracellular permeability by an antiproliferative factor from patients with interstitial cystitis. J Urol 2005;174:2382-7.

13. Ochodnicky P, Cruz CD, Yoshimura N, Michel MC. Nerve growth factor in bladder dysfunction: contributing factor, biomarker, and therapeutic target. Neurourol Urodyn 2011;30:1227-41.

14. Liu HT, Chen CY, Kuo HC. Urinary nerve growth factor levels in overactive bladder syndrome and lower urinary tract disorders. J Formos Med Assoc 2010;109:862-78.

15. Chung SD, Liu HT, Lin H, Kuo HC. Elevation of serum c-reactive protein in patients with OAB and IC/BPS implies chronic inflammation in the urinary bladder. Neurourol Urodyn 2011;30:417-20.

16. Kiuchi H, Tsujimura A, Takao T, Yamamoto K, Nakayama J, Miyagawa $\mathrm{Y}$, et al. Increased vascular endothelial growth factor expression in patients with bladder pain syndrome/interstitial cystitis: its association with pain severity and glomerulations. BJU Int 2009; 104:826-31.

17. Tamaki M, Saito R, Ogawa O, Yoshimura N, Ueda T. Possible mechanisms inducing glomerulations in interstitial cystitis: relationship between endoscopic findings and expression of angiogenic growth factors. J Urol 2004;172:945-8.

18. Li J, Micevych P, McDonald J, Rapkin A, Chaban V. Inflammation 
in the uterus induces phosphorylated extracellular signal-regulated kinase and substance $\mathrm{P}$ immunoreactivity in dorsal root ganglia neurons innervating both uterus and colon in rats. J Neurosci Res 2008;86:2746-52.

19. Keay SK, Szekely Z, Conrads TP, Veenstra TD, Barchi JJ Jr, Zhang $\mathrm{CO}$, et al. An antiproliferative factor from interstitial cystitis patients is a frizzled 8 protein-related sialoglycopeptide. Proc Natl Acad Sci U S A 2004;101:11803-8.

20. Keay S, Zhang CO, Kagen DI, Hise MK, Jacobs SC, Hebel JR, et al. Concentrations of specific epithelial growth factors in the urine of interstitial cystitis patients and controls. J Urol 1997;158:1983-8.

21. Keay S, Zhang CO, Hise MK, Hebel JR, Jacobs SC, Gordon D, et al. A diagnostic in vitro urine assay for interstitial cystitis. Urology 1998; 52:974-8.

22. Keay S, Zhang CO, Marvel R, Chai T. Antiproliferative factor, heparin-binding epidermal growth factor-like growth factor, and epidermal growth factor: sensitive and specific urine markers for interstitial cystitis. Urology 2001;57(6 Suppl 1):104.

23. Kim J, Keay SK, Dimitrakov JD, Freeman MR. p53 mediates interstitial cystitis antiproliferative factor (APF)-induced growth inhibition of human urothelial cells. FEBS Lett 2007;581:3795-9.

24. Keay S. Cell signaling in interstitial cystitis/painful bladder syndrome. Cell Signal 2008;20:2174-9.

25. Kim J, Keay SK, Freeman MR. Heparin-binding epidermal growth factor-like growth factor functionally antagonizes interstitial cystitis antiproliferative factor via mitogen-activated protein kinase pathway activation. BJU Int 2009;103:541-6.

26. Kim J, Freeman MR. Antiproliferative factor signaling and interstitial cystitis/painful bladder syndrome. Int Neurourol J 2011;15:18491.

27. Yang W, Chung YG, Kim Y, Kim TK, Keay SK, Zhang CO, et al. Quantitative proteomics identifies a beta-catenin network as an element of the signaling response to Frizzled-8 protein-related antiproliferative factor. Mol Cell Proteomics 2011;10:M110.007492.

28. Kim J, Ji M, DiDonato JA, Rackley RR, Kuang M, Sadhukhan PC, et al. An hTERT-immortalized human urothelial cell line that responds to anti-proliferative factor. In Vitro Cell Dev Biol Anim 2011; 47:2-9.

29. Simon LJ, Landis JR, Erickson DR, Nyberg LM. The Interstitial Cystitis Data Base Study: concepts and preliminary baseline descriptive statistics. Urology 1997;49(5A Suppl):64-75.

30. van de Merwe JP, Yamada T, Sakamoto Y. Systemic aspects of interstitial cystitis, immunology and linkage with autoimmune disorders. Int J Urol 2003;10 Suppl:S35-8.

31. Sugaya K, Nishijima S, Yamada T, Miyazato M, Hatano T, Ogawa Y.
Molecular analysis of adrenergic receptor genes and interleukin-4/ interleukin-4 receptor genes in patients with interstitial cystitis. J Urol 2002;168:2668-71.

32. Dimitrakov JD. A case of familial clustering of interstitial cystitis and chronic pelvic pain syndrome. Urology 2001;58:281.

33. Dimitrakov JD, Boyden SE, Freeman MR, Detchev IY, Tchitalov JI, Kunkel LM. Single nucleotide polymorphism (SNP) analysis of autosomal dominant interstitial cystitis: a family-based study [abstract]. J Urol 2005;173(4 Suppl):84. Meeting abstract no. 303.

34. Sebat J, Lakshmi B, Troge J, Alexander J, Young J, Lundin P, et al. Large-scale copy number polymorphism in the human genome. Science 2004;305:525-8.

35. Tuzun E, Sharp AJ, Bailey JA, Kaul R, Morrison VA, Pertz LM, et al. Fine-scale structural variation of the human genome. Nat Genet 2005;37:727-32.

36. Shoskes DA, Albakri Q, Thomas K, Cook D. Cytokine polymorphisms in men with chronic prostatitis/chronic pelvic pain syndrome: association with diagnosis and treatment response. J Urol 2002; 168:331-5.

37. Ritchie MD, Hahn LW, Roodi N, Bailey LR, Dupont WD, Parl FF, et al. Multifactor-dimensionality reduction reveals high-order interactions among estrogen-metabolism genes in sporadic breast cancer. Am J Hum Genet 2001;69:138-47.

38. Farrah T, Deutsch EW, Omenn GS, Campbell DS, Sun Z, Bletz JA, et al. A high-confidence human plasma proteome reference set with estimated concentrations in PeptideAtlas. Mol Cell Proteomics 2011; 10:M110.006353.

39. Deutsch EW, Eng JK, Zhang H, King NL, Nesvizhskii AI, Lin B, et al. Human Plasma Peptide Atlas. Proteomics 2005;5:3497-500.

40. Aebersold R, Mann M. Mass spectrometry-based proteomics. Nature 2003;422:198-207.

41. Hutchens TW, Yip TT. New desorption strategies for the mass-spectrometric analysis of macromolecules. Rapid Commun Mass Spectrom 1993;7:576-80.

42. Van QN, Klose JR, Lucas DA, Prieto DA, Luke B, Collins J, et al. The use of urine proteomic and metabonomic patterns for the diagnosis of interstitial cystitis and bacterial cystitis. Dis Markers 20032004;19:169-83.

43. Rabilloud T, Chevallet M, Luche S, Lelong C. Two-dimensional gel electrophoresis in proteomics: Past, present and future. J Proteomics 2010;73:2064-77.

44. Unlu M, Morgan ME, Minden JS. Difference gel electrophoresis: a single gel method for detecting changes in protein extracts. Electrophoresis 1997;18:2071-7.

45. Canter MP, Graham CA, Heit MH, Blackwell LS, Wilkey DW, Klein 
JB, et al. Proteomic techniques identify urine proteins that differentiate patients with interstitial cystitis from asymptomatic control subjects. Am J Obstet Gynecol 2008;198:553.e1-6.

46. Kuromitsu S, Yokota H, Hiramoto M, Morita S, Mita H, Yamada T. Increased concentration of neutrophil elastase in urine from patients with interstitial cystitis. Scand J Urol Nephrol 2008;42:45561.

47. Lemberger SI, Dorsch R, Hauck SM, Amann B, Hirmer S, Hartmann $\mathrm{K}$, et al. Decrease of Trefoil factor 2 in cats with feline idiopathic cystitis. BJU Int 2011;107:670-7.

48. Nagaraj N, Wisniewski JR, Geiger T, Cox J, Kircher M, Kelso J, et al. Deep proteome and transcriptome mapping of a human cancer cell line. Mol Syst Biol 2011;7:548.

49. Beck M, Schmidt A, Malmstroem J, Claassen M, Ori A, Szymborska $\mathrm{A}$, et al. The quantitative proteome of a human cell line. Mol Syst Biol 2011;7:549.

50. Wisniewski JR, Dus K, Mann M. Proteomic workflow for analysis of archival formalin fixed and paraffin embedded clinical samples to a depth of 10,000 proteins. Proteomics Clin Appl 2012 Oct 23 [Epub]. http://dx.doi.org/10.1002/prca.201200046.

51. Goo YA, Tsai YS, Liu AY, Goodlett DR, Yang CC. Urinary proteomics evaluation in interstitial cystitis/painful bladder syndrome: a pilot study. Int Braz J Urol 2010;36:464-78.

52. Huttenhain R, Soste M, Selevsek N, Rost H, Sethi A, Carapito C, et al. Reproducible quantification of cancer-associated proteins in body fluids using targeted proteomics. Sci Transl Med 2012;4:142ra94.

53. Fukui Y, Kato M, Inoue Y, Matsubara A, Itoh K. A metabonomic approach identifies human urinary phenylacetylglutamine as a novel marker of interstitial cystitis. J Chromatogr B Analyt Technol Biomed Life Sci 2009;877:3806-12.

54. Smolinska A, Blanchet L, Buydens LM, Wijmenga SS. NMR and pattern recognition methods in metabolomics: from data acquisition to biomarker discovery: a review. Anal Chim Acta 2012;750: 82-97.

55. Barding GA Jr, Salditos R, Larive CK. Quantitative NMR for bioanalysis and metabolomics. Anal Bioanal Chem 2012;404:1165-79.

56. Auffray C, Chen Z, Hood L. Systems medicine: the future of medical genomics and healthcare. Genome Med 2009;1:2.

57. Yang W, Kim Y, Kim TK, Keay SK, Kim KP, Steen H, et al. Integration analysis of quantitative proteomics and transcriptomics data identifies potential targets of frizzled-8 protein-related antiproliferative factor in vivo. BJU Int 2012 Jun 28 [Epub]. http://dx.doi.org/ 10.1111/j.1464-410X.2012.11299.x.

58. Hwang D, Rust AG, Ramsey S, Smith JJ, Leslie DM, Weston AD, et al. A data integration methodology for systems biology. Proc Natl
Acad Sci U S A 2005;102:17296-301.

59. Alon U. Biological networks: the tinkerer as an engineer. Science 2003;301:1866-7.

60. Barabasi AL, Gulbahce N, Loscalzo J. Network medicine: a networkbased approach to human disease. Nat Rev Genet 2011;12:56-68.

61. Gentleman RC, Carey VJ, Bates DM, Bolstad B, Dettling M, Dudoit S, et al. Bioconductor: open software development for computational biology and bioinformatics. Genome Biol 2004;5:R80.

62. Huang da W, Sherman BT, Lempicki RA. Systematic and integrative analysis of large gene lists using DAVID bioinformatics resources. Nat Protoc 2009;4:44-57.

63. Huang da W, Sherman BT, Lempicki RA. Bioinformatics enrichment tools: paths toward the comprehensive functional analysis of large gene lists. Nucleic Acids Res 2009;37:1-13.

64. Subramanian A, Tamayo P, Mootha VK, Mukherjee S, Ebert BL, Gillette MA, et al. Gene set enrichment analysis: a knowledge-based approach for interpreting genome-wide expression profiles. Proc Natl Acad Sci U S A 2005;102:15545-50.

65. Nakazato T, Bono H, Matsuda H, Takagi T. Gendoo: functional profiling of gene and disease features using $\mathrm{MeSH}$ vocabulary. $\mathrm{Nu}-$ cleic Acids Res 2009;37(Web Server issue):W166-9.

66. Wall DP, Pivovarov R, Tong M, Jung JY, Fusaro VA, DeLuca TF, et al. Genotator: a disease-agnostic tool for genetic annotation of disease. BMC Med Genomics 2010;3:50.

67. Xia J, Wishart DS. MSEA: a web-based tool to identify biologically meaningful patterns in quantitative metabolomic data. Nucleic Acids Res 2010;38(Web Server issue):W71-7.

68. Aranda B, Blankenburg H, Kerrien S, Brinkman FS, Ceol A, Chautard E, et al. PSICQUIC and PSISCORE: accessing and scoring molecular interactions. Nat Methods 2011;8:528-9.

69. von Mering C, Huynen M, Jaeggi D, Schmidt S, Bork P, Snel B. STRING: a database of predicted functional associations between proteins. Nucleic Acids Res 2003;31:258-61.

70. Shannon P, Markiel A, Ozier O, Baliga NS, Wang JT, Ramage D, et al. Cytoscape: a software environment for integrated models of biomolecular interaction networks. Genome Res 2003;13:2498-504.

71. Ogata H, Goto S, Sato K, Fujibuchi W, Bono H, Kanehisa M. KEGG: Kyoto Encyclopedia of Genes and Genomes. Nucleic Acids Res 1999; 27:29-34.

72. Kohler S, Bauer S, Horn D, Robinson PN. Walking the interactome for prioritization of candidate disease genes. Am J Hum Genet 2008; 82:949-58.

73. Vanunu O, Magger O, Ruppin E, Shlomi T, Sharan R. Associating genes and protein complexes with disease via network propagation. PLoS Comput Biol 2010;6:e1000641. 
74. Taylor IW, Linding R, Warde-Farley D, Liu Y, Pesquita C, Faria D, et al. Dynamic modularity in protein interaction networks predicts breast cancer outcome. Nat Biotechnol 2009;27:199-204.

75. Carro MS, Lim WK, Alvarez MJ, Bollo RJ, Zhao X, Snyder EY, et al. The transcriptional network for mesenchymal transformation of brain tumours. Nature 2010;463:318-25.

76. Gamper M, Viereck V, Geissbuhler V, Eberhard J, Binder J, Moll C, et al. Gene expression profile of bladder tissue of patients with ulcerative interstitial cystitis. BMC Genomics 2009;10:199.
77. Blalock EM, Korrect GS, Stromberg AJ, Erickson DR. Gene expression analysis of urine sediment: evaluation for potential noninvasive markers of interstitial cystitis/bladder pain syndrome. J Urol 2012;187:725-32.

78. Cheung W, Harel M, Abulafia O, Khan NH, Choi KK, Bluth MH, et al. Prevalence and characteristics of overactive bladder in women in a primary care setting [abstract]. J Urol 2009;181(4 Suppl):563 . Meeting abstract no. 1568. 